\title{
Negación del Holocausto en Chile: Miguel Serrano en los años ochenta
}

Gustavo Guzmán Castro gu.guzman@gmail.com Estudiante de Magíster en Historia, Universidad de Chile

\begin{abstract}
RESUMEN
El negacionismo es uno de los principales elementos ideológicos del nazismo contemporáneo. El presente artículo analiza su instalación y desarrollo en Chile durante los años ochenta de la mano del escritor Miguel Serrano y la consecuente reacción de la comunidad judía chilena. En él hemos considerado los libros de Serrano de este período, sus apariciones públicas, los actos masivos que organizó y la reacción de la comunidad judía expresada en sus órganos de prensa y otros medios de comunicación. Finalmente, se plantean proposiciones sobre la función que el negacionismo desempeñó al interior del nazismo chileno de los años ochenta.
\end{abstract}

\section{ABSTRACT}

The negationism is one of the main ideological elements of the contemporary Nazism. This article analyses its installation and development in Chile during the eighties thanks to the writer Miguel Serrano and the reaction of the Jewish community of Chile. We have considerate the Miguel Serrano's books of this period, his publicappearances, the public meetings organized by him and the reaction of the Jewish community expressed in the press. Finally, this article proposes some ideas about the function of the negationism for the Chilean Nazism of the eighties.

\section{PALABRAS CLAVE}

$$
\text { Revisionismo - Negacionismo - Antisemitismo en Chile - Negación del Holocausto }
$$


El revisionismo en torno al Holocausto -esto es, el intento por relativizar el número de víctimas judías, por minimizar la responsabilidad de Hitler en el genocidio, hasta el intento de negarlo por completo y culpar de la supuesta farsa al sionismo y al Estado de Israel, etc.constituye un elemento fundamental del discurso de la extrema derecha contemporánea, en particular del neonazismo. Surgido de las cenizas mismas de la Segunda Guerra Mundial, tendría como objetivo lavar la imagen del nacionalsocialismo, pues, si no hubo Holocausto, como afirman los negacionistas, ¿qué habría de malo con ser nazi? En Chile, el negacionismo intentó ser instalado desde fines de la década de 1970, por nazis y por simpatizantes de la causa árabe en el conflicto de Medio Oriente. El presente artículo se interesa por la instalación, el desarrollo y las expresiones del negacionismo nazi en Chile durante la década de 1980, de la mano del escritor Miguel Serrano, principal figura del nazismo chileno de las últimas décadas. Para hallar los orígenes del negacionismo nazi en Chile, sin embargo, es necesario remontarse a fines de la década de los setenta.

1978: instalación del negacionismo nazi en Chile

Tras varios años de residencia en el extranjero, en enero de 1978 el escritor y ex diplomáticoMiguel Serrano visitó Chile para clausurar los cursos de verano de la Universidad de Chile con una conferencia sobre Richard Wagner y Friedrich Nietzsche, en la Casa Central. La revista Cosasaprovechó su estadía en el país para entrevistarlo. En la ocasión, el periodista André Jouffé le preguntó por su pasado como diplomático, por los rumores que lo vinculaban sentimentalmente con Indira Gandhi y, por supuesto, por su declarada adhesión a Hitler y al nazismo. Ante su defensa del Tercer Reich, el periodista le recordó "que hubo un genocidio que nadie puede negar y dejar de aborrecer". Pero, según Serrano, "esa es la falsedad más grande del siglo veinte. Ya nadie lo cree en Europa. Después de la publicación de tres monumentales libros del profesor socialista francés Paul Rassinier: Las mentiras de Ulises, Ulises traicionado por sus amigos y La tragedia de los judíos europeos, salieron a la luz muchos mitos. Rassinier fue 
prisionero en un campo de concentración, en Buchenwald, específicamente. Él desmiente la existencia de las cámaras de gases y de asesinatos masivos"”.

La publicación de esta entrevista, en marzo de 1978, suscitó la inmediata reacción de la comunidad judía de Chile. La Palabra Israelitamanifestó su malestar conCosas por dar tribuna a un antisemita como Serrano:"la revista Cosasno ha hecho un servicio a la democracia con la publicación de las convicciones antisemitas del señor Serrano”². En la misma línea, el presidentedel Comité Representativo de Entidades Judías de Chile (CREJ), Gil Sinay, hizo llegar una carta de queja a la directora de la revista, Verónica López Helfmann, expresándole que "negar el Holocausto de seis millones de judíos constituye una afrenta a quienes fueron víctimas de esos actos inhumanos y un escarnio para los sobrevivientes, muchos de los cuales llevan todavía en sus brazos el indeleble sello que les imprimieron sus verdugos en los campos del infierno concentracionario"3.

Meses después, en septiembre de 1978, Serrano publicó su primer libro nazi, El Cordón Dorado. Hitlerismo Esotérico.En sus páginas, insistió en“decir de una vez por todas que ese asunto de los seis millones de judíos hechos desaparecer en los hornos crematorios es una de las más grandes farsas de la historia de la humanidad".Según él, "la invención de los seis millones de judíos muertos por el nazismo ha aportado a Israel, que no existía como Estado cuando aquel supuesto genocidio se cometiera, la astronómica suma de seis mil millones de libras esterlinas, pagadas en compensación a ese Estado por los alemanes". Para avalar estas afirmaciones,Serrano mencionó el libroHitler'sWar, del historiador inglés David Irving, cuya“conclusión es que Hitler no sabía nada de la exterminación de los judíos (...) si Hitler no sabía nada de tal exterminio es porque nunca existió".Pero David Irving no es el único autor revisionista que Serrano sugería a sus lectores,pues "si alguien se interesara por conocer en detalle la falsificación grandiosa de los seis millones de asesinados, debe leer la obra monumental del profesor francés Paul Rassinier. Sus libros se titulan: Las Mentiras de Ulises, publicado en París, en 1949; Ulises traicionado por los suyos, publicado en 1960; El verdadero proceso de Eichmann, publicado en 1962, y El Drama de los judíos Europeos, publicado en 1964. (...) Otro importante documento es la investigación del profesor universitario inglés Richard Harwood (seudónimo): 
Didsixmillionreally die? (¿Murieron realmente seis millones?), publicado por "HistoricalReviewPress", en Inglaterra. Harwood continúa el trabajo de Rassinier con publicaciones sobre el Proceso de Nuremberg. También el libro del profesor norteamericano A. R. Butz: TheHoax of theTwentieth Century (La Mistificación del Siglo XX)”4.

Tal como sucedió con la entrevista deCosas, la publicación de El Cordón Doradoprovocó lareacción de la dirigencia comunitaria judía. Gil Sinay publicó en La Palabra Israelita una serie de diecisiete breves artículos dedicados a refutar las argumentaciones negacionistas que Miguel Serrano intentaba instalar en Chile. En el primer artículo de la serie se advierte que

\begin{abstract}
"En los últimos tiempos se observa en muchos países la tendencia a negar, a debilitar la inhumanidad del crimen cometido por los nazis con la aniquilación de millones de judíos durante el periodo hitleriano.

Este infame intento de parte de algunos escritores y propúsculos [sic] antisemitas se ha observado también por desgracia en nuestro país, y cabe recordar las declaraciones del sedicente literato Sr. Miguel Serrano, en la revista "Cosas" en que glorifica la memoria de este gran criminal del siglo XX.

Por esta razón, creemos de nuestro deber exponer ante la opinión pública de este país, la realidad del Holocausto, para que sirva de enseñanza a las actuales y futuras generaciones". (La Palabra Israelita, $n^{\circ} 1183,8$ de septiembre de 1978, p. 3)
\end{abstract}

Del mismo modo, la Federación Sionista de Chileadvirtió, desde las páginas de Mundo Judío, sobre el peligro de la campaña que intentaba desarrollarse en Chile:

"La campaña neo nazi mundial ha llegado a Chile.

Desde diversos puntos del mundo una acción muy bien concertada, basada en datos apócrifos y apoyada por la eterna "mala memoria" de la humanidad, pretende negar la existencia del Holocausto y reivindicar la memoria de Adolfo Hitler. (...) Diversas publicaciones nacionales han dado tribuna a los viejos o nuevos nazis, muchos de ellos anónimos. Todos, sin excepción, justifican el genocidio, ya sea directamente, ya sea por la vía de negar su existencia. (...) La Comunidad Judía de Chile debe saber que sin estridencias, con seriedad, pero decidida energía, debemos salir al paso de esta acción, y que cada uno tiene un compromiso ineludible en esta tarea".(Mundo Judío, n 1814, 21 de septiembre de 1978, p. 14.)

Pero las reacciones a la publicación deEl Cordón Dorado no provinieron sólo de la comunidad judía. En general, la prensa escrita se mostró poco acogedora con el libro de Serrano. El Mercurio, por ejemplo, recibió el libro con evidente ironía: "Condimentos: Hitler está vivo, es un iniciado, un inmortal. Lo busco en la Antártida y en los Himalayas. Tuvo la bomba atómica. Chile será la Nueva 
Israel. Los judíos padecen de "impureza fundamental”. No son un pueblo. Hitler nunca exterminó

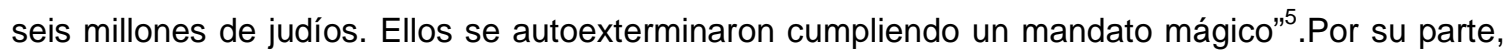
el crítico literario de Las Últimas Noticias, Luis Sánchez Latorre,resumió su opinión sobre el libro al afirmar que "tal vez haya sólo una monstruosidad comparable con el asesinato de seis millones de seres humanos: aseverar que este crimen nunca se perpetró”6. La Tercera entrevistó a Serrano para preguntarle acaso “¿hubo o no hubo seis millones de judíos muertos en los campos de concentración de Alemania?". Su respuesta, la de siempre:

\begin{abstract}
"No, no hubo seis millones de judíos. Yo eso se lo rebato con argumentos sólidos. Tengo libros que le puedo facilitar, de enemigos jurados del nazismo, que objetivamente dicen que no creen en las cámaras de gases y que con los recursos que había en ese tiempo era prácticamente imposible que se eliminara a tanta gente. Ahora, los judíos no sólo creen en esto, sino que les da muy buenos dividendos (...) ellos han montado una operación piedad en todo el mundo que les ha rendido los mejores dividendos. Si ir más lejos, el Estado alemán occidental les lleva pagados ya seis mil millones de libras esterlinas como compensación al Estado de Israel, que no existía jurídicamente en tiempos de este pretendido genocidio. Y tendrán que seguir pagándoles hasta el año 2000. Como usted puede ver, los seis millones de muertos les están rindiendo bastantes beneficios. Ahora, ése es sólo uno de los beneficios. El otro es que los judíos pueden hacer lo que quieran con los palestinos. Los han expulsado de sus tierras, los han perseguido, los han bombardeado, los han masacrado y ¿quién ha reclamado por este genocidio? Nadie, porque los judíos pobrecitos sufrieron tanto, los persiguieron tanto, que no importa que hagan lo que se les ocurra. Nadie llora por los niños palestinos masacrados por las bombas de napalm. Esos no existen ¿verdad? Para ellos no hay derechos humanos, porque rigen sólo para los judíos”.(La Tercera, 22 de octubre de 1978, pp. 8-9)
\end{abstract}

A fines de 1978 Miguel Serrano dejó Chile para volver a su residencia en la Suiza italiana, donde vivía desde que la elección presidencial de Salvador Allende pusiera fin a su carrera diplomática. Pasarían varios años antes de que volviera a lograr figuración pública por su antisemitismo.

1984: funeral de Rauff, ampliafiguración pública

A mediados de mayo de 1984, pocas semanas después de que el gobierno de Pinochet negara a Israel su expulsión del país y de que la "cazadora de nazis"BeateKlarsfeld visitara Chile para promover su extradición a Alemania Federal, el criminal de guerra nazi Walter Rauff murió de un ataque al corazón en su casa de Las Condes. Una vez terminado su funeral, llevado a cabo en el Cementerio General, y una vez que su familia hizo abandono del lugar, tres personas se 
acercaron al borde de su tumba y, levantando su brazo derecho, gritaron "Heil Hitler!Heil Walter Rauff!". Entre esas personas estaba Miguel Serrano.

Un nazi chileno, vestido con un abrigo de cuero negro, haciendo el saludo nazi al final del funeral de un connotado criminal de guerra, todo esto en un país gobernado por una dictadura militar. La imagen -que no tardó en dar la vuelta al mundo- resultó irresistible para los periodistas apostados en el lugar, quienes abordaron a Serrano para preguntarle por los cargos que pesaban sobre Rauff y por el rol que le cupo durante el Holocausto. En las páginas de El Mercuriose destacaba que, según Serrano, "no es efectivo que Walter Rauff creara las cámaras de gas portátiles. Esa es una falsedad que ya fue desterrada en Europa"”. En Las Últimas Noticias, por su parte, se señalaba que los crímenes atribuidos a Rauff eran "un disfraz judío para apoderarse del mundo. Jamás ocurrió lo que ellos llaman holocausto. Los camiones de gas fueron una burda mentira contra Rauff".

Serrano cumplió con creces su objetivo: la imagen del saludo nazi a Rauff dio la vuelta al mundo, obtuvo una amplia figuración pública, atrajo la atención de los medios de prensa escritos y de los noticieros televisivos, y logró instalar la negación del Holocausto en la opinión pública chilena.No fue sorpresivo que, tras la performance del cementerio, Serrano fueraentrevistado por varios de los principales diarios de Santiago.EnLa Segunda, afirmó tener varios amigos judíos y que "si mañana viera que van a meter judíos a un horno crematorio, yo me quemo con ellos"'. Se refirió, además, a la recompensa ofrecida por el InstituteforHistoricalReview ${ }^{10}$ de California: "Nunca se pudo probar que haya existido una cámara de gas. En Estados Unidos, un grupo de revisionistas de la historia ofreció 50 mil dólares a quien les presentara una prueba de una cámara de gas. Hasta el día de hoy, nunca se ha presentado nadie. Es una operación planetaria hecha para mantener la idea de que el nacionalsocialismo era una cosa diabólica"11. En la entrevista deLas Últimas Noticias volvió a referirse a las acusaciones que pesaban sobre Rauff: "Todo falso. Una invención. $Y$ no lo afirman los alemanes, sino franceses norteamericanos e ingleses, en documentos indesmentibles. En largas y serias investigaciones" ${ }^{\prime 2}$.

Pero las entrevistas no acabaron ahí. A comienzos de septiembre se publicó una extensa entrevista en la Revista del Domingo de El Mercurio, marcadamente complaciente,y en la que 
Serrano pudo expresar sus convicciones antisemitas con total libertad, además de promocionar la aparición de su próximo libro ${ }^{13}$.

Ese libro era Adolf Hitler, el Último Avatara, su segundo libro nazi y el más importante de sus textos antisemitas. Durante su lanzamiento, llevado a cabo el 9 de septiembreen el tradicional Café Santos de Santiago, el autor, acompañado de un grupo de jóvenes nazis, invitó a los asistentes a desmitifcar el "holocausto, pieza maestra de la propaganda sionista, muy útil para justificar la usurpación de Palestina o para extorsionar a los alemanes"14.En el libro, Serrano sugería que

"La misma prisión a Rudolf Hess cumple con este objetivo de mantener siempre viva la memoria del nazismo en el pueblo judío y sus servidores. $Y$ el siniestro Wiesenthal, inventando "criminales de guerra" y "cazándolos" en los más apartados rincones de la tierra. El caso de Walter Rauff es ilustrativo para los chilenos. El complot de los seis millones de asesinados en los campos de exterminio nazis se agita constantemente, pendiendo con su sombra fantasmal sobre la humanidad entera. Además, sirve para financiar la mantención del Estado de Israel, cuya misión principal ha sido la de recibir a todos los judíos pobres del mundo, especialmente de Rusia, aglutinarlos y militarizarlos. Los alemanes siguen pagando sumas enormes por indemnización".(Miguel Serrano, Adolf Hitler, el Último Avatara, Santiago, Nueva Edad, 1984, p. 303.)

Tal como en 1978, la amplia figuración pública lograda por Serrano ese año, gracias a la performance del cementerio y a la publicación de El Último Avatara, volvió a movilizar la reacción de la dirigencia comunitaria judía.

El editor de La Palabra Israelita, Gregorio Goldenberg, cuestionó a la prensa escrita, en particular a El Mercurio, por la cabida que Serrano encontraba en sus publicaciones: “¿De quién o de quiénes, entonces, depende que se convierta en noticias las infames y venenosas "declaraciones" de Miguel Serrano? (...) Creo que, como chileno, tengo derecho a saber qué piensa al respecto el señor Agustín Edwards, propietario de la empresa y Director del periódico y su Suplemento".Goldenbergapostó por apelar a la ética profesional de estos medios, en particular de El Mercurio y sus publicaciones asociadas. Según él, "un nazi como Miguel Serrano, cuya fotografía haciendo el saludo nazi en la supuesta tumba de Walter Rauff circuló por el mundo entero, no puede ser noticia. Eso pienso no como judío, sino como periodista profesional, con un 
compromiso con la verdad, la justicia y los Derechos Humanos, compromiso que está por encima de toda otra consideración"15.

En "Peligro: nazis en acción", publicado por La Palabra Israelita en octubre de ese año, el abogado AmitiPilowskillamó la atención sobre la publicación, circulación y venta en las librerías de Santiago de Adolf Hitler, el Último Avatara, y sobre la acogedora bienvenida dada por la prensa a esta publicación nazi: "Nos asombra, por ejemplo, la forma benevolente como El Mercurio ha acogido -sin espíritu crítico ni advertencia alguna a sus lectores- las ideas de Serrano. Alguien hay allí que da luz verde para que Serrano proclame entre otras barbaridades que los hornos crematorios no existieron ¿Por qué goza de esta protección el señor Serrano? El Mercurio no puede ignorar que lo menos que podía hacer este artículo era herir la susceptibilidad de los judíos"16.

Por su parte, El Vocero, órgano de prensa de la comunidad sefaradí de Chile, publicó una nota de la dirigencia comunitaria judía de Chile "ante escalada nazi". En la nota, "el Comité Representativo de las Entidades Judías de Chile se dirigió al Sr. Agustín Edwards, Presidente de la Empresa Periodística El Mercurio, haciéndole llegar una enérgica protesta a raíz de una publicación de la Revista del Domingo a Miguel Serrano"17.

Por último, La Palabra Israelita dedicó la editorial del último ejemplar de 1984 a refutar el negacionismo de Serrano y volvió a publicar la serie de artículosantinegacionistasde 1978, para contrarrestar el nuevo intento de instalar en Chile la negación del Holocausto como un objeto de interés y de discusión para la opinión pública:"en los últimos tiempos se observa en muchos países la tendencia a negar y debilitar la inhumanidad del crimen cometido por los nazis al aniquilar a seis millones de judíos durante el período hitleriano. Este infame intento de parte de algunos escritores y grupúsculos antisemitas se ha observado también por desgracia en nuestro país, con el envío de cartas a diarios y revistas en forma evidentemente orquestada. Cabe recordar también las declaraciones y escritos del sedicente literato señor Miguel Serrano que glorifica la memoria del gran criminal del siglo XX”. En estas líneas, Gil Sinaydefiende la estrategia adoptada por el CREJ para responder a las provocaciones nazis de Serrano y a su intento de instalar el negacionismo en Chile, y justifica las constantes respuestas de la dirigencia comunitaria judía, al establecer que "el 
esclarecimiento y la confrontación política e intelectual con el nazismo, son siempre los medios más importantes para combatir este peligro, y debe combatirse la proliferación de la literatura neonazi". Sinay concluye la editorial sugiriendo que, al igual que en algunos países europeos, en Chile la negación del Holocausto sea considerada delito: "no hay duda que este camino de incorporar la negación del Holocausto como un hecho delictuoso es el más acertado, y debe ser captado por todas las naciones realmente democráticas para impedir que no vuelvan a consumarse hechos que son vergüenza de la historia y un baldón para la Humanidad”18.

1985:Las Últimas Noticias y la "polémica del Holocausto"

Con motivo del cuadragésimo aniversario de la liberación del campo de exterminio de Auschwitz,en enero de 1985 Las Últimas Noticiasentrevistó a Nicolás Acs, un sobreviviente del Holocausto avecindadoen Chile. En la oportunidad, este anciano judío húngaro dio testimonio de su experiencia personal durante el genocidio nazi, de la suerte que corrieron muchos de sus amigos y familiares, y de su vida en Chile. Al final de la entrevista fue consultado por los dichos de Miguel Serrano, en los que negaba la existencia del Holocausto. Su respuesta fue "pues que venga y lo diga frente a mín"19.

A petición del propio Serrano, Las Últimas Noticiaslo entrevistó cuatro meses después, dándole la oportunidad de replicar a Nicolás Acs: "Quiero desmentir, porque tengo amigos judíos que seguramente creen en el holocausto. $Y$ no quiero, por motivo alguno, que me relacionen con esta pesadilla imaginaria”. El periodista replicó preguntando“¿no existieron ni la matanza ni las cámaras?", a lo que Serrano contestó:"Jamás. El señor Acs jamás vio alguna. Y varios escritores e investigadores franceses, ingleses, norteamericanos y judíos, jamás han encontrados pruebas de que existiera una sola cámara de gas". Para apoyar sus dichos se refiere a las obras revisionistas de Rassinier, Faurisson, Harwood, Irving y Butz, además de las deBrug y Kautzky, autores judíos. Serrano concluye la entrevista con una pregunta dirigidaal periodista"¿Sabe usted cuál fue el verdadero holocausto? La expulsión de alemanes desde Polonia, en 1945. En el éxodo murieron cuatro millones"20. 
A partir de ese momento, se desarrolló en las páginas de Las Últimas Noticias la "polémica del Holocausto" ${ }^{21}$. Una semana después de la entrevista a Serrano, fue entrevistado el presidente del Comité Representativo de Entidades Judías de Chile (CREJ), Isidoro Gorodischer, quien descalificó cualquier opinión de un nazi como Serrano sobre el Holocausto e insinuó un posible desorden siquiátrico del escritor ${ }^{22}$.Siete días más tarde se publicó una carta de Serrano, en la queafirmaba que"tampoco las declaraciones del señor Gorodischer aportan pruebas sobre la existencia real del holocausto”. En la misiva, Serrano se dirigía directamente a Gorodischer: “¿De qué crímenes se trata? ¿De la matanza de seis millones de judíos? Pruébela. ¿Las "cámaras de gas"? Pruebe que existieron. Y si tiene estas pruebas, mándelas a la siguiente dirección: “InstituteforHistoricalReview”. P.O. Box 1306. Torrence, California 90505. U.S.A. Si esas pruebas son reales le pagarán 50.000 dólares y serán publicadas en la prensa. Periodistas de prestigio, historiadores y científicos se encuentran entre los que las juzgarán ${ }^{23}$.Todos nos enteraremos de ello. $\mathrm{Y}$ yo me habré convencido"24.

Gorodischer volvió a ser entrevistado por Las Últimas Noticias, dándole la oportunidad de replicar a la carta de Serrano. Sin embargo, Gorodischer descartócualquier posible discusión o diálogo al establecer que "no polemizaremos con Miguel Serrano. Podremos abrir diálogo con cualquier otra persona en torno a estos temas, pero no con Serrano". El periodista preguntó entonces “¿Es su posición personal o la del Comité Representativo de las Entidades Judías de Chile, señor Gorodischer?", a lo que Gorodischer respondió que“es la decisión del Comité. No ayudaremos a hacer la apología del nacismo [sic] ni ayudaremos a que se tergiverse, como se está haciendo en muchos países, la historia. La negación de los crímenes del nacismo”25.

A esta altura, habían tomado parte de la "polémica del holocausto" deLas Últimas Noticias lectores comunes y corrientes, quienes "tomaron partido" entre la posición de Serrano y la defendida por el CREJ. Entre mayo y julio de ese año Las Últimas Noticias publicó siete de estas cartas.Creemos que allí radica parte del triunfo obtenido por Serrano con esta polémica epistolar: instalar la negación del Holocausto como un tema discutible, como una discusión en la que es posible y lícito tomar partido. 
La polémica llegó a tal punto que inclusola Embajada de Israel, por medio de su Oficina de Prensa, se hizo parte por medio de una carta ${ }^{26}$.Pero el activismo nazi del año 1985 no se limitó a la actividad epistolar de Miguel Serrano y de lectores que solidarizaban con él. Durante ese año se produjo una proliferación de propaganda, panfletos y rayados antisemitas en las calles de Santiago y otras ciudades de Chile. Tanto que la directiva del CREJ hizo llegar su preocupación al Ministerio del Interior ${ }^{27}$.

1986-1989: activismo nazi y reacción del CREJ

Estos fueron años de gran actividad para Miguel Serrano. Entre mediados de 1986 y mediados de 1989 escribió varios libros "hitleristas", prologó y editó algunos "clásicos" del antisemitismo y encabezó masivos actos de proselitismo nazi. Sin embargo, estos agitados años de activismo nazi se vieron acompañados por un cambio en la forma en que el CREJ enfrentó las provocaciones de Serrano y su intento de instalar una "agenda" de extrema derecha neonazi en Chile. Así como en el período que va desde 1978 a mediados de 1986 el CREJ respondió regularmente a las apariciones públicas de Serrano, en especial en aquellas en que aparecía negando la existencia del Holocausto, en el período que va desde mediados de 1986 a mediados de 1989 -eventualmente, esto se ha proyectado en el tiempo, aunque con excepciones- la estrategia adoptada consistió en un silencio sepulcral respecto de sus publicaciones, de sus figuraciones públicas, de su activismo como editor de obras antisemitas, etc. Pese a la incesante actividad pública de Serrano entre los años 1986 y 1989, el CREJ hizo como que éste no hubiera existido.

En 1986 Serrano publicó tres libros nazis de su autoría: en junio,Nacionalsocialismo, única solución para los pueblos de América del sur ${ }^{28}$; en agosto, El ciclo racial chileno ${ }^{29}$; y, en octubre, La resurrección del héroe ${ }^{30}$. Todos ellos financiados, publicados y distribuidos por él mismo.A comienzosde 1987 prologó la reedición deRaza Chilena ${ }^{31}$ de Nicolás Palacios -edición financiada por Carlos Cardoen. En mayo, publicóContra la usura ${ }^{32}$ de Gottfried Feder, con un prólogo propio. En julio,publicóEl Plan Andinia. Estrategia Sionista para apoderarse de la Patagonia argentina y 
chilena $^{33}$, también prologado por él. Finalmente, en septiembre, so pretexto del aniversario de la Matanza del Seguro Obrero, organizó un masivo acto de homenaje al recién fallecido Rudolf Hess, en el Cementerio General ${ }^{34}$.En 1988 encabezó una edición de los Protocolos de los Sabios de Sión, clásico texto antisemita, bajo el título deLos Protocolos de los Sabios de Sión y su aplicación en Chile ${ }^{35}$. El nombre de la publicación estaba dado por el prólogo que Serrano escribió e incluyó en la edición. Cabe mencionar que esta edición se hizo en colaboración con la agrupación neonazi española CEDADE.La oportunidad para distribuir públicamente el texto vino en septiembre del mismo año, cuando Serrano encabezó un acto de homenaje por los cincuenta años de la Matanza del Seguro Obrero en el Cementerio General ${ }^{36}$.En abril de 1989, al cumplirse cien años del nacimiento de Hitler, Serrano organizó y encabezó un acto de homenaje al dictador alemán en la precordillera de Santiago. A la ceremonia asistió la prensa escrita y grupos de nazis provenientes de varios países, incluida Alemania $^{37}$.

Recapitulando, entre 1986 y la primera mitad de 1989 Serrano escribió tres libros nazis (Nacionalsocialismo, única solución para los pueblos de América del Sur, El ciclo racial chileno; La resurrección del héroe), prologó y editó en Chile tres "clásicos" del antisemitismo (Los Protocolos de los Sabios de Sión y su aplicación en Chile; El Plan Andinia. Estrategia sionista para apoderarse de la Patagonia argentina y chilena; Contra la usura) y organizó tres actos de proselitismo nazi (homenaje a Rudolf Hess, quincuagésimo aniversario de la Matanza del Seguro Obrero, celebración de los cien años del natalicio de Hitler). Es decir, entre 1986 y la primera mitad de 1989 asistimos a la etapa de mayor activismo nazi en la carrera de Miguel Serrano. Sin embargo, y como ya adelantáramos, durante esta etapa varió la forma en la que el CREJ enfrentaba la figuración pública de Serrano. Hasta ese punto la respuesta del CREJ era inmediata y explícita, reprobando y denunciando sus intentos de situar una "agenda" nazi en la sociedad chilena. Recordemos que en 1984 Gil Sinay había defendido la idea de que"el esclarecimiento y la confrontación política e intelectual con el nazismo, son siempre los medios más importantes para combatir este peligro" ${ }^{\text {”3 }}$. Sin embargo, desde 1987 en adelante el CREJ no acusó recibo ni respondió, ni en sus órganos de prensa ni en la prensa escrita de circulación nacional, a ninguna de las apariciones públicas de Serrano. Desde 1986, cuando el CREJ tomó conocimiento de la publicación de 
Nacionalsocialismo, única solución para los pueblos de América del Sur y lo denunció ante las autoridades, el CREJ no volvió a responder a las provocaciones de Serrano. La estrategia consistió en hacer como si Serrano no existiera, de modo de no hacer eco de sus figuraciones públicas. Creemos que este cambio de estrategia fue adelantado por Isidoro Gorodischer a mediados de 1985 cuando, en medio de la "polémica del Holocausto", estableció que "no polemizaremos con Miguel Serrano. Podremos abrir diálogo con cualquier otra persona en torno a estos temas, pero no con Serrano", aclarando que esta no era una opción personal sino "la decisión del Comité. No ayudaremos a hacer la apología del nacismo [sic] ni ayudaremos a que se tergiverse, como se está haciendo en muchos países, la historia. La negación de los crímenes del nacismo" ${ }^{\text {"39. }}$.

Esta nueva estrategia se mantuvo incólume hasta julio de 1989, cuando El Mercurio publicó la siguiente carta de Gil Sinay, presidente del CREJ:

"Señor director:

A raíz del interesante artículo de don Enrique Lafourcade, titulado "Miguel Serrano. Solo ante el mundo", aparecido en el diario "El Mercurio" del domingo 18 de junio, se han publicado diversas cartas, entre ellas una del propio Serrano.

La negación del Holocausto es un método recurrente al cual apelan los nazis por razones que desbordan los marcos ideológicos para entrar derechamente en el campo de la psiquiatría.

Por respeto a nuestros hermanos inmolados en la más salvaje acción que recuerda la historia de la humanidad y al dolor de los sobrevivientes, y por respeto asimismo al pueblo de Chile que tiene suficientemente sanidad mental y conocimientos como para caer en este juego, en ningún caso vamos a polemizar con los seguidores del nazismo.

Deseamos sólo alertar a la opinión pública a no ser sorprendida por un grupúsculo que hace del odio y de la mentira su bandera y que, con un afinamiento muy sospechoso, sueña con un nuevo Hitler para la humanidad". (El Mercurio, 10 de julio de 1989, p. A2.)

¿Qué provocó esta fisura en la nueva estrategia del CREJ? Serrano acababa de publicar en Chile El Informe Leuchter ${ }^{40}$.

\section{El Informe Leuchter en Chile}

En 1984 el gobierno de Canadá demandó ante los tribunales de justicia al ciudadano alemán, nacionalizado canadiense, Ernst Zündel, por estimular el antisemitismo con la publicación y distribución de material que él sabía falso. Por medio de su editorial,SamisdatPublications, 
Zündelpublicaba y distribuía textos antisemitas y negacionistas, como Didsixmillionreally die? deRichard Harwood, en Norteamérica y Europa ${ }^{41}$. En 1985 Zündel fue encontrado culpable y sentenciado a quince meses de prisión, pero gracias a la apelación de su defensa, basada en errores de procedimiento durante el proceso, debió hacerse un segundo juicio. Éste se hizo célebre por la comparecencia de connotados autores negacionistas al estrado, para testificar a favor del Zündel, como Robert Faurisson y David Irving. Sin embargo, fue la irrupción del "especialista" estadounidense en métodos de ejecución y cámaras de gas, Fred Leuchter, la que marcó el desarrollo final del proceso.Financiado por la defensa de Zündel, Leuchter encabezó un grupo de "investigación" (que incluía un cineasta, un camarógrafo y un traductor) en algunos de los campos nazis de exterminio situados en territorio polaco. El grupo visitó los campos de Auschwitz/Birkenau y de Majdanek, desde donde obtuvo ilegalmente fragmentos de los viejos edificios y "evidencia forense", los cuales habrían sometido a "pruebas científicas" que arrojaron como conclusión la inexistencia de las cámaras de gas. La investigación y las conclusiones fueron plasmadas en un informe que luego fue presentado por la defensa de Zündel ${ }^{42}$ en el juicio, TheLeuchterReport: AnEngineeringReportontheAllegedExecution Gas Chambers at Auschwitz, Birkenau and Majdanek, Poland, publicado por la editorial de Zündel, SamisdatPublications ${ }^{43}$. Serrano editó este informe en Chile a mediados de 1989, con un prólogo en el que homenajeaba tanto a ErnstZündel como a Fred Leuchter:

\begin{abstract}
"Es sólo ahora, hace muy poco y gracias al proceso que se ha seguido en Canadá a Ernst Zündel, que al fin la verdad total, definitiva, irrefutable, ha venido a ser declarada al mundo por un especialista norteamericano en cámaras de gas, el ingeniero Fred A. Leuchter, quien investigó a Auschwitz, Birkenau y Majdanek, en Polonia, llegando a la conclusión absoluta de que allí jamás existió una sola cámara de gas utilizada para asesinar a un solo judío. $\mathrm{Y}$ esto es definitivo, histórico y para siempre. La Mentira siniestra ha sido científicamente demostrada como tal. La verdad se ha impuesto, gracias a la valentía de un científico, a su capacidad, a su honestidad y, sobre todo, al sacrificio de un hombre, Ernst Zündel".(Miguel Serrano, El Informe Leuchter, pp. 9-10.)
\end{abstract}

La publicación de El Informe Leuchter en Chile, por parte de Miguel Serrano, marca el hito más importante del negacionismo en Chile. Aunque el recurso de negar el Holocausto como forma de lograr figuración pública (y publicidad para sus libros, editados por él mismo) había sido utilizado por Serrano desde fines de los setenta, nunca antes había ocupado el negacionismo tal centralidad 
en alguno de sus libros. Nunca antes había publicado un texto negacionista en Chile, limitándose a sugerirlos. Además, El Informe Leuchter se muestra como un texto aparentemente científico y objetivo, sin inclinaciones antisemitas. Pareciera lejano, muy lejano a las fantasías propias de los Protocolos de Sión. Sin embargo, la finalidad de su publicación es la misma de cualquier texto negacionista: lavar la imagen del nazismo a la vez que se insulta la memoria de las víctimas del nazismo, transformándolas de objetos de la violencia nazi en autores de una falsificación histórica gigantesca:

"Mentira el holocausto, mentira las cámaras de gas, mentira las lámparas hechas con piel humana, los jabones con grasa de judíos; mentira los crímenes de guerra nazi y mentira los "criminales de guerra" y los "torturadores", mentira el Diario de Ana Frank".(Miguel Serrano, El Informe Leuchter, pp. 9-10.)

La aparición de El Informe Leuchter significó un quiebre en la estrategia que el CREJ había adoptado para enfrentar el activismo nazi de Serrano y la censura generalizada de parte de la prensa escrita y los círculos literarios. En las páginas de El Mercurio Enrique Lafourcade publicó "Miguel Serrano: solo contra el mundo", donde ironiza con el tránsito operado por Serrano en su carrera literaria, con su paso de buen escritor a nazi estrafalario ${ }^{44}$. Por supuesto, Serrano respondió con una carta titulada "No estoy solo" en la que defiende el "valor de su obra" ${ }^{45}$. También Luis Sánchez Latorre, crítico literario de Las Últimas Noticias se dio tiempo para comentar el libro, de manera similar a como lo hizo Lafourcade ${ }^{46}$. Entonces, si negar el Holocausto despierta una oposición y una censura generalizada, ¿para qué hacerlo?

¿Para qué negar el Holocausto?

Sabemos que el revisionismo en torno al Holocausto nació de las cenizas mismas de la Segunda Guerra Mundial ${ }^{47}$ y que constituye una de las características fundamentales del discurso de la extrema derecha de las últimas décadas ${ }^{48}$, pero ¿paraqué se niega el Holocausto? Y, en particular, ¿qué perseguía Miguel Serrano al instalar y desarrollar el negacionismo en el Chile de los años ochenta? 
El primer paso de Serrano consistió en instalar la negación del Holocausto en la prensa escrita. En innumerables ocasiones afirmó, en entrevistas y otras apariciones públicas, que el Holocausto era una farsa con la que Israel obtenía dinero de Alemania y con la que podía justificar la usurpación de tierras palestinas. De tanto repetirlo, lo instaló como un tema de discusión en la opinión pública y logró que su "postura" sobre el Holocausto fuera considerada como "el otro bando" de una discusión lícita, legítima. Para ello, la prensa escrita de la época le prestó una ayuda invaluable. En el mejor de los casos, la prensa escrita fue "provinciana" y hasta ingenua al dar tribuna para que Serrano negara el Holocausto incesantemente y lograra, finalmente, revestir de cierta legitimidad pública su discurso antisemita. En el peor de los casos, diarios como El Mercurio y Las Últimas Noticias actuaron con negligencia y faltando a la ética profesional al permitir las constantes expresiones antisemitas de Miguel Serrano, durante toda la década de los ochenta. En cualquiera de los casos, las empresas de Agustín Edwards fueron las más útiles para los fines de Serrano.

El intento de instalar la negación del Holocausto como objeto de interés y de debate en la opinión pública chilena a través de la prensa fue exitoso. La "polémica del Holocausto" en las páginas de Las Últimas Noticias, a mediados de 1985, es la mejor prueba de ello. Varios lectores escribieron apoyando la "posición" de Miguel Serrano, y otros tantos condenándola. Sin embargo, el éxito radica precisamente en el hecho que se dé dicho "debate", en el hecho de que se le conceda a los negacionistas el lugar de "el otro punto de vista" sobre el Holocausto. Es precisamente esta concesión a los negacionistas de ser "el otro lado", "la otra postura", lo que Deborah Lipstadt quería evitar a toda costa cuando publicó DenyingtheHolocaust.

Creemos que el éxito de Serrano en la instalación del discurso negacionista influyó considerablemente en el giro operado al interior del CREJ para enfrentar su activismo antisemita. Es probable que la dirigencia comunitaria de la época considerara que seguir respondiendo sistemática y explícitamente a cada una de las provocaciones de Serrano ayudaba, involuntariamente, a hacer eco de tales provocaciones, favoreciéndole. Según esta lógica, el silencio y el soslayo permitirían minimizar el impacto de las figuraciones de Serrano. 
Una vez que se ha instalado en la opinión pública, una vez que ha logrado constituirse en un objeto de discusión, en un tema opinable, el negacionismo se transforma en una plataforma desde la cual se puede lavar la imagen de la extrema derecha en general, y del nazismo en particular. Como ya hemos mencionado, si no existió el Holocausto, ¿qué hay de malo con ser nazi? Y, una vez blanqueada la imagen del nazismo, una vez que se desembaraza del genocidio, las posibilidades de crecimiento, de hacerse de un espacio de expresión política, aumentan. En todo caso, en el caso de Serrano, el interés principal no estará en el crecimiento del nazismo chileno, en un renacer político de los nacionalsocialistas, sino en mejorar las ventas de sus libros. Es que, desde que dejó la diplomacia a principios de los años setenta con la llegada de Salvador Allende a La Moneda, los ingresos económicos del escritor habían menguado considerablemente.

El negacionismo de los años ochenta permitió a Serrano expresar ciertas posturas ideológicas de extrema derecha y antisemitas en la prensa escrita de circulación nacional, manifestarlas en el espacio público y revestirlas de una cierta legitimidad ("el otro punto de vista sobre el Holocausto"). Permitió, además, sacar ciertas manifestaciones antisemitas del reducido círculo de fanáticos del que provienen y, bajo la apariencia de investigaciones científicas, darlas a conocer el público chileno. Le permitió un espacio de figuración y de influencia cultural que bien pudo ser utilizado, no sólo para blanquear el nazismo, sino para intentar rearmar una extrema derecha chilena. Sin embargo, insistimos, Serrano capitalizó este espacio de figuración y esta publicidad con la venta de sus libros nazis.

\section{REFERENCIAS BIBLIOGRÁFÍCAS}

CARO, Isaac. Extremismos de derecha y movimientos neonazis. Berlín, Madrid, Santiago. Santiago, LOM, 2007.

CASALS, Xavier. Ultrapatriotas. Extrema derecha y nacionalismo de la guerra fría a la era de la globalización. Barcelona, Crítica, 2003.

COHN, Norman. El mito de la conspiración judía mundial: los Protocolos de los Sabios de Sión.Madrid, Alianza, 1983. 
GOODRICK-CLARKE, Nicholas. Hitler's Priestess.Savitri Devi, the Hindu-Aryan Myth and Neonazism.New York, New York University Press, 1998.

GOODRICK_CLARKE, Nicholas. Black Sun. Aryan Cults, Esoteric Nazism and the Politics of Identity.New York, New York University Press, 2002.

LIPSTADT, Deborah. Denying the Holocaust.The Growing Assault on Truth and Memory.New York, Plume, 1994.

PEREDNIK, Gustavo. La judeofobia. Barcelona, Flor del Viento, 2001.

SCHMIDT, Michael. La Alemania neonazi. Barcelona, Anaya \& Mario Muchnik, 1995.

SERRANO, Miguel. El Cordón Dorado. Hitlerismo Esotérico. Santiago, Edicioneself, 1978.

SERRANO, Miguel. Adolf Hitler, el último Avatara. Santiago, La Nueva Edad, 1984.

SERRANO, Miguel. El ciclo racial chileno. Santiago, 1986.

SERRANO, Miguel. Nacionalsocialismo, única solución para los pueblos de América del Sur. Santiago, 1986.

SERRANO, Miguel.La resurrección del héroe. Santiago, 1986.

SERRANO, Miguel. Contra la usura. Santiago, 1987.

SERRANO, Miguel. El Plan Andinia. Estrategia Sionista para apoderarse de la Patagonia Chilena y Argentina. Santiago, 1987.

SERRANO, Miguel. Los Protocolos de los Sabios de Sión y su aplicación en Chile. León, Wotan, 1988.

SERRANO, Miguel. El Informe Leuchter. Fin de una mentira. Santiago, 1989.

TAGUIEFF, Pierre-André. La nueva judeofobia.Barcelona, Gedisa, 2003.

${ }^{1}$ Cosas n³7, 2 de marzo de 1978, pp. 26-28.

${ }^{2}$ La Palabra Israelita, $n^{\circ} 1160,24$ de marzo de 1978, p. 3.

${ }^{3}$ La Palabra Israelita, $n^{\circ} 1181,25$ de agosto de 1978, p. 5.

${ }^{4}$ Miguel Serrano, El Cordón Dorado. Hitlerismo Esotérico, Santiago, Edicioneself, 1978, pp. 202205.

${ }^{5}$ El Mercurio, 17 de septiembre de 1978, p. E8. 
${ }^{6}$ Las Últimas Noticias, 4 de noviembre de 1978, p. 5.

${ }^{7}$ El Mercurio, 16 de mayo de 1984, p. C5.

${ }^{8}$ Las Últimas Noticias, 16 de mayo de 1984, p. 11.

${ }^{9}$ La Segunda, 18 de mayo de 1984, pp. 14-15.

${ }^{10}$ El IHR es una de las principales organizaciones de la extrema derecha contemporánea. Detrás de la apariencia de una institución científica hay una organización antisemita que pretende aportar "pruebas" que niegan la existencia del Holocausto e intentan limpiar la imagen del nazismo. Michael Schmidt, La Alemania neonazi, Barcelona, Anaya \& Mario Muchnik, 1995, pp. 270-272.

${ }^{11}$ La Segunda, 18 de mayo de 1984, pp. 14-15.

${ }^{12}$ Las Últimas Noticias, 19 de mayo de 1984, p. 17.

${ }^{13}$ Revista del Domingo de El Mercurio, 2 de septiembre de 1984, pp. 11-12.

${ }^{14}$ Las Últimas Noticias, 10 de septiembre de 1984, p. 16.

${ }^{15}$ La Palabra Israelita, n¹460, 14 de septiembre de 1984, p. 3.

${ }^{16}$ La Palabra Israelita, n¹462, 5 de octubre de 1984, pp. 1 y 7.

${ }^{17}$ El Vocero, n69, 1 de octubre de 1984, p. 6.

${ }^{18}$ La Palabra Israelita, $n^{\circ} 1474,28$ de diciembre de 1984, p. 3.

${ }^{19}$ Las Últimas Noticias, 31 de enero de 1985.

${ }^{20}$ Las Últimas Noticias, 13 de mayo de 1985, p. 9.

${ }^{21}$ Las Últimas Noticias, 7 de junio de 1985, p. 12.

${ }^{22}$ Las Últimas Noticias, 20 de mayo de 1985, p. 7.

${ }^{23}$ Esta recompensa fue ofrecida por el InstituteforHistoricalReview en su Primera Convención Revisionista, en 1979. En la ocasión, el director del IHR, Lewis Brandon, seudónimo de William David McCalden, anunció una recompensa de US\$50.000 a quien probara que los nazis utilizaron cámaras de gas para exterminar judíos durante la Segunda Guerra Mundial. Deborah Lipstadt, Denying the Holocaust. The Growing Assault on Truth and Memory, New York, Plume, 1994, p. 137.

${ }^{24}$ Las Últimas Noticias, 27 de mayo de 1985, p. 12.

${ }^{25}$ Las Últimas Noticias, 28 de mayo de 1985, p. 12. 
${ }^{26}$ Las Últimas Noticias, 11 de junio de 1985, p. 10.

${ }^{27}$ La Palabra Israelita, $n^{\circ} 1491,24$ de junio de 1985, p. 1.

${ }^{28}$ Miguel Serrano, Nacionalsocialismo, única solución para los pueblos de América del Sur. Santiago, 1986.

${ }^{29}$ Miguel Serrano, El ciclo racial chileno. Santiago, 1986.

${ }^{30}$ Miguel Serrano, La resurrección del héroe. Santiago, 1986.

${ }^{31}$ Nicolás Palacios, Raza chilena. Santa Cruz, Ediciones Colchagua, 1987.

${ }^{32}$ Miguel Serrano y Gottfried Feder, Contra la usura. Santiago, 1987.

${ }^{33}$ Miguel Serrano, El Plan Andinia. Estrategia sionista para apoderarse de la Patagonia argentina y chilena. Santiago, 1987.

${ }^{34}$ Las Últimas Noticias, 6 de septiembre de 1987, p. 17.

${ }^{35}$ Miguel Serrano, Los Protocolos de los Sabios de Sión y su aplicación en Chile. León, Wotan, 1988.

${ }^{36}$ La Tercera, 6 de septiembre de 1988, p. 36.

${ }^{37}$ La Tercera, 21 de abril de 1989, p. 12.

${ }^{38}$ La Palabra Israelita, $n^{\circ} 1474,28$ de diciembre de 1984, p. 3.

${ }^{39}$ Las Últimas Noticias, 28 de mayo de 1985, p. 12.

${ }^{40}$ Miguel Serrano, El Informe Leuchter, Santiago, 1989.

${ }^{41}$ Deborah Lipstadt, op. cit., pp. 157-158.

${ }^{42}$ Ernst Zündel habría tenido su primer contacto con el negacionismo nazi a través de SavitriDevi, en los años sesenta. "Savitri Devi was the first to suggest to Zündel that the Nazi genocide of the Jews was untrue. Zündel went on to make a career out of Holocaust denial (...) When she relayed this myth of French origin to the young Zündel in the 1960s, Savitri Devi could scarcely have imagined the world audience that he would gain for Holocaust denial through his court cases and appeals by the end of the 1980s". Nicholas Goodrick-Clarke, Hitler's Priestess. Savitri Devi, the Hindu-Aryan Myth and Neonazism, New York, New York University Press, 1998, p. 207.

${ }^{43}$ Deborah Lipstadt, op. cit., pp. 162-163.

${ }^{44}$ El Mercurio, 18 de junio de 1989, p. D23. 
${ }^{45}$ El Mercurio, 25 de junio de 1989, p. A2.

${ }^{46}$ Las Últimas Noticias, 2 de julio de 1989, p. 34.

47، “La ultraderecha que emergió en la posguerra (...) relativizó los crímenes cometidos por el Eje y negó el Holocausto judío". Xavier Casals, Ultrapatriotas. Extrema derecha y nacionalismo de la guerra fría a la era de la globalización, Barcelona, Crítica, 2003, p. 8.

${ }^{48}$ Pierre-André Taguieff, La nueva judeofobia, Barcelona, Gedisa, 2003, p. 140. 